\title{
Migración boliviana y escuela secundaria en Argentina: reflexiones en clave intercultural
}

\author{
Bolivian migration and secondary school in Argentina: \\ reflections in intercultural key \\ Gabriela Novaro \\ Universidad de Buenos Aires - Conicet \\ gabriela.novaro@gmail.com
}

\section{Resumen}

Las políticas educativas argentinas comenzaron en los últimos años a dar lugar a los enfoques interculturales y habilitaron dispositivos escolares específicos para la población indígena. En su implementación concreta las propuestas denominadas interculturales suelen limitarse a los primeros años de la escolaridad. La escolarización de los jóvenes migrantes y descendientes de migrantes no es atendida en su particularidad por estas políticas. El trabajo de investigación que desarrollo en contextos familiares, comunitarios y escolares en una localidad de Buenos Aires con un componente importante de población procedente de Bolivia pone en cuestión esta situación. La atención a las voces y experiencias de padres, referentes comunitarios, jóvenes y docentes muestra los múltiples desafíos en clave intercultural que el contexto migratorio plantea a las escuelas. En particular me detengo en los avances y límites de las escuelas secundarias de la localidad para trabajar con la condición transnacional de vida de los jóvenes y dar lugar a la apuesta simultanea de ellos y sus familias por mantener su distintividad como colectivo e incluirse en la sociedad argentina.

Palabras clave: Escuela secundaria, migración, inclusión, interculturalidad, juventud.

\begin{abstract}
Argentine educational policies began in the last years to incorporate intercultural focus allowing specific dispositives for the indigenous population. In their actual implementation so called intercultural proposals are generally limited to the first years of schooling. Schooling of young migrants and migrant descendants is not atended in its particularities-specificities by these policies. The research I develop in families, community and school contexts, in a neighbourhood of Buenos Aires with a high component of bolivian migrants, poses this issue. Paying attention to the voices and experiences of fathers, community leaders, young and teachers, shows the various challenges, that the intercultural perspective poses to schools in migratory contexts. I focus in the advances and limits of secondary schools in the neighbourhood to work with the transnational condition of life of these young, and to take into account the double intention, of
\end{abstract}

Gabriela Novaro

Migración boliviana y escuela secundaria en Argentina: reflexiones en clave intercultural. Autoctonía. Revista de Ciencias Sociales e Historia, Vol. III, N2, Julio-Diciembre 2019, 111-131 ISSN 0719-8213

DOI: http://doi.org/10.23854/autoc.v3i2.133 
these young and their families to maintain their distinctivity as a collective group, while to be included in the Argentine society.

Keywords: High school, migration, inclusion, interculturality, youth.

\section{Introducción}

En Argentina los trabajos sobre la niñez y la juventud migrante tienen ya varios años de desarrollo pero deben seguir siendo profundizados. Gran parte de estos trabajos se focalizan en las trayectorias educativas. Desde ese recorte venimos avanzando desde el año 2004 en proyectos de investigación socioantropologica desarrollados en la Universidad de Buenos Aires. De unos años a esta parte nos hemos centrado crecientemente en el dialogo, los encuentros y desencuentros entre contextos formativos escolares y no escolares. Lo mismo resulta un aspecto fundamental a profundizar en la investigación y la definición de políticas educativas en contextos de diversidad. A partir del 2010 focalicé mi trabajo en la situación de los niños y las escuelas primarias de un barrio de la provincia de Buenos Aires habitado en una proporción significativa por migrantes provenientes de Bolivia y por sus descendientes. En el 2016 comencé a trabajar en las escuelas secundarias de la misma localidad. La atención a la articulación entre la escuela y las situaciones formativas que suceden fuera de ella implico una consideración creciente de las voces y expectativas de las familias, las organizaciones de migrantes y los mismos jóvenes.

Comienzo el texto presentando brevemente como el tema de la migración y la educación es abordado en la agenda política y en la investigación. Me detengo luego en los avances del trabajo etnográfico desarrollado desde el año 2010. La reflexión sobre registros observacionales, charlas informales y entrevistas y también sobre actividades de apoyo a iniciativas educativas de la localidad, me permite recuperar las voces y experiencias de las familias, referentes comunitarios, jóvenes y actores escolares. Entiendo que estas voces y expectativas deben ser objeto de reflexión y consideración al momento de definir políticas sociales y educativas.

La investigación en espacios familiares y comunitarios permitió identificar la centralidad prácticas (por ejemplo el trabajo, los viajes a Bolivia, las festividades cívicas bolivianas) asociadas a la transmisión intergeneracional en las que se proyecta la continuidad del colectivo boliviano. Considerando las expectativas de las familias, 
organizaciones comunitarias y de los mismos jóvenes registro un aspecto de sus demandas que resulta difícil escuchar e incorporar en las escuelas: la expectativa simultanea de incluirse en la sociedad de destino y de mantener referencias fuertes al territorio de origen.

Argumento en este texto que las políticas de inclusión e interculturalidad en Argentina han permitido visibilizar presencias no legitimas $\mathrm{y}$ voces silenciadas en las escuelas (tal como las de los jóvenes bolivianos y descendientes); pero también que en el sistema educativo (en particular en el nivel secundario) siguen fuertemente vigentes mandatos asimilacionistas y nacionalizadores desde los cuales se dificulta abordar la condición transnacional de vida de los jóvenes que las transitan. Esta situación ya registrada a nivel de la escuela primaria, adquiere particularidades en las escuelas secundarias. Sostengo que en este nivel educativo se advierten avances pero también dificultades de la escuela para considerar y valorar las experiencias formativas de los jóvenes de familias migrantes que transcurren en espacios familiares y comunitarios. Estas dificultades limitan las posibilidades de que la escuela dialogue con experiencias formativas que el colectivo considera fundamentales para mantener su continuidad. En la escuela simultáneamente se habilita la pregunta por el sentido formativo de estas prácticas, pero siguen vigentes visiones que a priori asocian el trabajo y la movilidad a dificultades para la continuidad del ciclo escolar y que suponen que la participación en espacios festivos comunitarios obturan la identificación con lo nacional argentino. En el texto me detengo en las festividades nacionales en espacios comunitarios y escolares intentando identificar los distintos sentidos de lo nacional que se juegan en ellas, las continuidades y discontinuidades que adquieren en espacios comunitarios y escolares y sobre todo el protagonismo de los jóvenes bolivianos en ambos.

\section{Interculturalidad, escuela secundaria y mi- gración: ¿un tema de la agenda política?}

La inmigración en Argentina coincidió con la conformación del Estado nacional entre fines del siglo XIX y principios del XX. La política estatal fomentó en esos años la migración europea para poblar un territorio supuestamente despoblado. La migración llego en estos años a constituir el 30\% de la población. Desde el discurso dominante se plasmó la imagen de una nación blanca, descendiente de los europeos (Gordillo y Hirsch, 2010). Las escuelas argentinas fueron parte importante de este proceso. A partir de 1910, en un contexto de creciente conflictividad política y social, se produjeron en el sistema educativo numerosos proyectos para nacionalización de la enseñanza. Se reiteran políticas y discursos que exaltan la idea de que las escuelas deben revivir el patriotismo, contraponerse a la inmigración ácrata y disolvente (Monitor de la Educación Común, 1910), convertir a los alumnos en cruzados de la argentinidad (programas educativos de 1939). Se hace evidente en estos términos la centralidad de los proyectos de asimilación en articulación con formas excluyentes 
del nacionalismo y la exaltación de sentimientos de rechazo a lo extranjero. En este contexto la función asignada a la escuela fue básicamente integrar borrando las marcas de origen de la población (la indígena, la rural y la migrante pobre). (Novaro, 2016).

En años posteriores se consolida una imagen que contrapone la valoración de la migración europea asociada al progreso de la Argentina, con la migración latinoamericana presentada como "un problema" (Pacecca 2010). Este supuesto problema, vale aclarar, refiere hoy en día al componente más alto de la población migrante en Argentina ${ }^{2}$. Tambien la escuela fue un actor fundamental en la instalación de esta imagen polar (Novaro, 2005).

La coexistencia del mandato nacionalista de la escuela y de esas imágenes discriminatorias sobre la población latinoamericana resulta en fuertes tensiones con los discursos más recientes de inclusión e interculturalidad.

En Argentina los debates en torno a la interculturalidad y la educación se instalaron en el discurso de estado en la década del 90 en el marco de políticas sociales y educativas de corte "compensatorio".

Es necesario destacar que de la mano de la interculturalidad se visualizaron presencias y habilitaron voces históricamente silenciadas en el sistema educativo. El discurso de la diversidad y la interculturalidad ha permitido discutir (aunque aun tímidamente) con las formas excluyentes del nacionalismo y con el paradigma civilizatorio que estructuró el sistema educativo argentino en el que los indígenas eran definidos como otros. Los avances en este sentido fueron muchos, pero las deudas tambien lo son.

Las denominadas políticas interculturales suponen que la interculturalidad es una situación que caracteriza a la población indígena ${ }^{3}$ (Hecht et al., 2015; Diez, 2014; Padawer et al., 2017). Los colectivos migrantes, en particular los migrantes latinoamericanos en Argentina, no son considerados en la ley nacional como destinatarios de estas políticas.

Esta omisión puede interpretarse de distintos modos: el presupuesto de que la procedencia nacional no necesariamente implica marcas de distintividad que la escuela deba considerar, la persistencia del paradigma nacionalista asimilacionista. Lo cierto es que los colectivos migrantes quedan de este modo ubicados en un limbo. No considerados ni en las políticas diferenciadas, ni en las políticas comunes y universales que, aunque reformuladas siguen siendo en gran medida poco atentas a la situación de quienes se alejan de los parámetros de identificación hegemónicos.

La situación de los migrantes procedentes de Bolivia pone claramente en evidencia estas limitaciones. Esta población se define en general desde su adscripción nacional, pero reconoce que muchas de sus prácticas cotidianas incluyen ele- 
mentos asociados a pertenencias indígenas andinas (Grimson, 1999; Caggiano, 2014). Suma asi su marca como "población extranjera" y como población indígena o descendiente de indígenas. Esta suma constituye un aspecto más para su abordaje desde una perspectiva intercultural.

Pero además de la presencia velada de la población migrante en las políticas interculturales, hay otros velos y otras ausencias. En su implementación concreta la interculturalidad se considera sobre todo en propuestas para los primeros años de la escolaridad. Es significativa la disminución de estudiantes, establecimientos de esta modalidad y docentes especializados en interculturalidad a medida que se avanza en los niveles educativos (UNIPE, 2019).

El nivel secundario tiene una deuda en este sentido y por eso en este artículo nos centramos en él, mas aun considerando que la ley educativa vigente afirma la obligatoriedad de este nivel. Distintas investigaciones sostienen que en la escuela secundaria muestra profundas dificultades para superar la lógica selectiva y jerárquica que históricamente tuvo en Argentina; también para incorporar innovaciones en su estructura y en la lógica disciplinar y fragmentada del conocimiento (Terigi, 2015; Toscano y Diez, 2012).

La discontinuidad en el trabajo desde la interculturalidad en el nivel secundario es en sí misma un dato. Esto lleva a preguntarnos por la posible persistencia de distintos presupuestos no explícitos: el supuesto de que la interculturaldiad es solo un tema de los primeros años, de que un enfoque intercultural se reduce a objetivos instrumentales al inicio de la escolaridad para reforzar trayectorias que una vez transitadas con más éxito deben ser continuadas por políticas comunes donde las particularidades se borren en pos de la uniformidad, la asociación del nivel secundario a un trayecto donde el joven puede alejarse, sin demasiados costos, de las referencias culturales y los conocimientos de sus grupos familiares. En estos presupuestos, es evidente que las particularidades siguen siendo un problema, las diferencias, una marca a borrar. Desde ya, no acordamos con estos supuestos. Creemos que estos presupuestos se legitiman entre algunos actores educativos, e incluso entre algunos especialistas, en un hecho complejo pero que no podemos negar: en Argentina al menos, las propuestas diferenciadas (entre otras las escuelas de modalidad intercultural bilingüe) siguen teniendo grandes dificultades para no ser asociadas a circuitos de escolarización devaluada. Resta aun desarrollar investigaciones sistemáticas que puedan pensar distintos modos de definir la calidad educativa y también identificar qué aspectos de esta posible devaluación se asocian a factores escolares, y cuales a contextos socioeconómicos y diferentes posibilidades de acceso a bienes culturales de los colectivos de referencia.

Es necesario reparar también en que junto con los avances y límites de las políticas interculturales, la escolarización de la población migrante aparece propiciada por otras normativas. Tanto la ley de migración vigente (aunque creciente- 
mente cuestionada por la gestión política actual) como la ley educativa resultan auspiciosas en términos de acceso a derechos y continuidad de los ciclos escolares de la población migrante ${ }^{4}$; tal como se enuncian, sin embargo, no incluyen la consideración de sus particularidades por lo que estos derechos podrían limitarse a la mera presencia en las escuelas.

Los datos cuantitativos muestran la concurrencia prácticamente masiva de la población migrante boliviana al sistema de educación primaria (UNICEF, 2015). Para el nivel secundario, en cambio, la proporción de quienes se encuentran asistiendo a algún establecimiento educativo es significativamente más baja que la observada para el total de población de la Argentina (Cerruti y Binstock, 2012) ${ }^{5}$.

A pesar de la mayor igualdad en el plano legal y de la presencia sobre todo en el nivel primario, el trabajo etnográfico que desde el año 2004 desarrollamos en escuelas primarias de distintas localidades de la Ciudad de Buenos Aires (en particular en la zona sur de la ciudad) y la provincia de Buenos Aires nos ha permitido poner en duda que esta mera presencia se asocie a situaciones de igualdad. En textos previos relevamos el tránsito de esta población por circuitos escolares de menor prestigio, el desconocimiento de sus trayectorias educativas y de sus múltiples experiencias formativas, las bajas expectativas de desempeño escolar, las dificultades para concretar trayectos educativos largos, el silenciamiento de sus palabras, de sus pertenencias y saberes, el mantenimiento del mandato de integración con lo nacional argentino. Considerando como decíamos la masiva presencia de estos niños en la escuela primaria, creemos que el término que cabe para describir esto es el de inclusión subordinada (Novaro et al., 2011).

En la escuela secundaria, la caída de la matricula de la población migrante, y en particular de la migración proveniente de Bolivia habla por sí misma de la desigualdad en la inclusión. Creemos que también suman a la desigualdad las formas en que la escolaridad transcurre entre quienes efectivamente asisten a las escuelas. En este sentido nos proponemos avanzar a partir del trabajo etnográfico en una localidad en particular, pero relevando procesos y relaciones que consideramos significativos para pensar la escuela en múltiples espacios marcados por la migración.

\section{Interculturalidad, escuela secundaria y mi- gración en la investigación socioeducativa}

Abordar la situación educativa secundaria en contextos de migración hace necesario, además de considerar las precisiones sobre interculturalidad y educación del acápite anterior, recuperar los desarrollos sobre juventud migrante y sobre segundas generaciones de distintas regiones.

En los estudios migratorios en Europa y Estados Unidos la situación de los jóvenes migrantes y los "descendientes" viene siendo objeto de creciente atención. El trabajo de Sayad con los 
migrantes argelinos en Francia resulta un antecedente ineludible sobre este tema. Interesa recuperar la tensión que Sayad registra entre la nacionalidad francesa atribuida por el estado y el sentimiento de pertenencia al colectivo de sus padres en los jóvenes de familias argelinas que nacieron en Francia (Sayad, 2010). Diversas investigaciones europeas advierten el contenido extranjerizante y estigmatizante de la utilización de categorías como segunda generación, hijos de... en tanto definen a los hijos por una acción de los padres (migrar) (Borrego, 2003; Gil Araujo y Pedone, 2013).

En EEUU la atención a los niños migrantes y descendientes de migrantes se ha realizado muy pegada a la preocupación por la inserción educativa (Portes y Rumbaut, 2010) y el costo que para la misma implican las dificultades que experimentan los hijos de inmigrantes en tanto buscan equilibrar la orientación de los padres extranjeros con las demandas de "asimilación" de la sociedad receptora. La preocupación por el "éxito" en la escuela ha llevado a preguntarse por las distintas formas de asimilación y la posibilidad de coexistencia de proyectos familiares por insertarse y mantener sus referencias de origen. En este sentido se definen y despliegan categorías como aculturación selectiva que permiten pensar en una "alianza intergeneracional" para la adaptación exitosa. Este tipo de términos se correlacionan con formas de pensar las identificaciones de las nuevas generaciones en un lugar estratégico entre la sociedad de origen de sus familias y la sociedad de destino. La noción de aculturación selectiva ha sido debatida por sus supuestos prescriptivos, por presuponer el carácter positivo de la asimilación y por omitir la gran diversidad de situaciones y matices. La antropología de la educación en EEUU ha cuestionado la suposición de que la asimilación es positiva y la culpabilización de las familias por la falta de asimilación y el fracaso escolar (Bartlett et al., 2015; Gibson, 1998; Gibson \& Koyama, 2011). Desde abordajes cualitativos y etnográficos se ha relevado la complejidad de la condición transnacional de los estudiantes latinos atravesados por situaciones de discriminación y racismo (Hamman y Zuñiga, 2011; Orellana, 2009).

Las investigaciones sobre juventud migrante en Latinoamérica reconocen antecedentes entre muchos otros en los trabajos de México y Brasil (Santos, 2014; Oliveira, 2017; Demartini, 2012).

En Argentina los trabajos sobre juventud y migración tienen tambien varios años de desarrollo y han atendido a aspectos como la participación de los jóvenes en grupos artísticos (Gavazzo, 2014) la migración y el trabajo de los jóvenes (Pacecca, 2010). Desde el equipo de investigación que coordino en la Universidad de Buenos Aires venimos trabajando desde hace años sobre un campo poco explorado (la educación y la migración) pero que reconoce antecedentes en trabajos como el de Domenech en Córdoba (2013) Trpin en Rio Negro, (1987) y Neufeld en Buenos Aires (1999). 


\section{Educación, migración e interculturalidad desde una aproximación etnográfica. Aproxi- maciones en clave local}

\subsection{El barrio y el trabajo de campo}

Desde el año 2010 desarrollo mi investigación en contextos familiares, comunitarios y escolares de un barrio de la localidad de Escobar, distante $50 \mathrm{~km}$ de la Ciudad de Buenos Aires. Este barrio está habitado en una proporción significativa por migrantes e hijos de migrantes provenientes de zonas rurales de Potosí (Bolivia). El espacio se caracteriza por el fuerte proceso asociativo, concentrado en las actividades de la Colectividad Boliviana de Escobar. Esta institución nuclea a cerca de 1000 socios, sostiene actividades productivas hortícolas, de comercialización de vegetales y textiles y mantiene fuertes vinculaciones con organismos del Estado argentino y boliviano. Organiza además numerosas actividades festivas y recreativas que convocan a los niños y jóvenes. Las familias provenientes de Bolivia mantienen fuertes asociaciones con este país: contacto con parientes, viajes permanentes, emprendimientos económicos que vinculan uno y otro territorio.

En la localidad hay dos escuelas públicas primarias, linderas a dos escuelas públicas secundarias. Una en la salida hacia el centro de Escobar (la denomino por eso la escuela de la ruta); otra, en la plaza del centro del barrio, cercana a los terrenos de la Colectividad (conocida por algunos como la escuela de los bolivianos, pero que prefie- ro llamar la escuela de la plaza). Estas escuelas, como enseguida veremos, ofrecen una oferta educativa que en muchos sentidos (condiciones edilicias, estabilidad del equipo docente, etc.) es muy desigual.

A lo largo de estos años recorrí espacios familiares (momentos cotidianos de la vida doméstica, traslado a las escuelas, llegada de parientes de Bolivia, compra y venta en los mercados), conversé e interactué innumerables veces con referentes comunitarios de la Colectividad Boliviana de Escobar (en particular las autoridades y secretarios de cultura y de comunicación), asistí a festividades cívicas y religiosas (festejo del 6 de agosto- dia de la independencia de Bolivia, del dia de Potosí, día de los muertos, carnavales). A partir del año 2013, sin abandonar los recorridos previos, comencé a realizar actividades en las escuelas primarias (registro de documentos escolares, charlas con docentes y con alumnos, asistencia a clases, colaboración en el desarrollo de algunas secuencias de ciencias sociales, presencia en festividades y salidas educativas). En el año 2016 comencé a trabajar en las escuelas secundarias.

Todo este recorrido se realizó desde un enfoque etnográfico que implico asistencias semanales al barrio, entrevistas, charlas informales y registros observacionales (individuales y en los últimos años en ocasiones también colectivos). Incluyó además la consulta de documentación educativa y un relevamiento estadístico de las características socioeconómicas y educativas del barrio. 
El trabajo combinó situaciones de registro etnográfico y la colaboración en diversas actividades educativas: además de la contribución con clases y salidas didácticas de las escuelas, apoyé un proyecto de alfabetización de mujeres bolivianas; recientemente (junto con integrantes del equipo de investigación que coordino en la Universidad de Buenos Aires) comencé a participar en la producción y emisión de programas de educacion en la radio de la Colectividad.

El trabajo sistemático en la escuela secundaria como recién mencioné, comenzó en el año $2016^{6}$. Ese año trabajamos en la secundaria de la llamada escuela de la ruta. En el año 2018 profundizamos los contactos con la escuela secundaria de la plaza, asistimos a las festividades patrias de la escuela, acompañamos el desarrollo de una secuencia sobre la conquista de América en segundo año y entrevistamos a todos los alumnos de una de las secciones de este año.

Este trabajo se sostiene en gran medida en los registros del trabajo desarrollado en las escuelas secundarias, sobre todo durante el 2018, pero también en la revisión de registros anteriores procurando focalizar en las interpelaciones identitarias a los jóvenes y las visiones sobre la escuela en los referentes de las organizaciones y en las familias.

\section{Las expectativas educativas de las familias y organizaciones hacia los jóvenes ¿Es la inter- culturalidad un reclamo social?}

En contextos familiares y comunitarios advertí la continuidad de la preocupación en torno a la identificación nacional de las jóvenes generaciones. En innumerables diálogos con familiares y referentes de las organizaciones de migrantes estos expresaban su interés porque "no se pierdan las raíces", "los chicos sepan de donde vienen”, “ellos son bolivianos, pero de segunda generación".

En la Colectividad se explicita la expectativa de inclusión y participación política de los jóvenes en la organización, en emprendimientos productivos como los mercados de venta frutas y verduras y de vestimenta, y en actos, con gran evidencia en los festivos.

En estos diez años esta preocupación en muchos casos se trasladó de las segundas, a las terceras generaciones.

La dinámica migratoria en Argentina, los fuertes procesos de estigmatización y discriminación de los migrantes latinoamericanos, la particular forma en que el colectivo boliviano se inserta en la localidad de Escobar hacen necesario aclarar desde un inicio que la continuidad de la referencia a Bolivia, más que asociada a una posición nostálgica, debe entenderse como una condición de reproducción social. Desde allí es posible comenzar a comprender la preocupación recurrente por sostener a Bolivia como referencia de las jóvenes generaciones. No debemos perder de vista que esto se da en un con- 
texto donde permanentemente la permanencia y del retorno son tema de debate.

Las festividades cívicas bolivianas (especialmente el 6 de agosto) son un espacio privilegiado para registrar los posicionamientos y las apuestas identitarias del colectivo. Ocasión para el despliegue de símbolos que marcan un territorio como propio, idealizan el espacio dejado y señalan la continuidad del pasado y las proyecciones en el nuevo espacio. Las fiestas definen un espacio y tiempo habilitado para visibilizar el carácter binacional de la colectividad boliviana en el barrio y de "los descendientes".

Los festejos muestran a la vez la intención de permanecer acá, y de sostener la referencia a Bolivia. Himnos, banderas, escarapelas de los dos países adornan los palcos y son portadas por los participantes, concursos de danzas folklóricas argentinas y bolivianas, palabras de autoridades políticas de la embajada y el consulado, pero también del municipio y la provincia. El sentido de continuidad con lo boliviano es fuerte y atraviesa las distintas generaciones: los grupos desfilan con trajes de las distintas regiones de Bolivia, año a año los discursos sostienen imágenes similares (los niños llevan a Bolivia en la sangre, nos enseñan a defender lo nuestro, que las tradiciones no se pierdan).

También se registra la expectativa de mantener a Bolivia como referencia de los jóvenes en una iniciativa discutida hace años en la Colectividad y que no logra concretarse: la creación de una escuela boliviana en el barrio asociada a la enseñanza de lo andino, lo quechua, lo boliviano. Proyecto discutido en asambleas de socios, pero que, al menos hasta ahora, no termina de concretarse.

Los saberes y prácticas asociados a Bolivia se registran también en contextos familiares. Se advierte el interés por transmitir a los niños y jóvenes la lengua quechua, la danza, el tejido, la cocina boliviana. Registramos reiteradamente la proyección a los niños de videos sobre bailes y programas televisivos de Bolivia y Perú. En forma recurrente se expresa la intención de sucesión en los espacios familiares de trabajo (ferias y mercados). Otra situación recurrente se advierte en la apuesta por el carácter revelador que podría tener un viaje a Bolivia entre los hijos de bolivianos. Para muchas familias el viaje a Bolivia representa un momento para presentar a los parientes que han quedado allá a los niños y jóvenes nacidos acá y para que sus hijos no se olviden de donde vienen (Novao, 2016).

En contextos familiares se registra también la preocupación porque en sus formas expresivas y comunicativas sus hijos mantengan la imagen de niños y jóvenes educados, asociada a Bolivia. La preocupación por la transmisión de "una forma de ser" asociada a lo boliviano con atributos como respetuoso, trabajador, obediente, se fortalece en la representación del contacto con argentinos como contaminante y potencial fuente de contagio (sobre todo entre los jóvenes) de prácticas como el robo, las drogas, el alcohol. 
En definitiva, proyectos que consolidan el sentido de adscripción a Bolivia como condición de pertenencia al grupo de parentesco y a la comunidad. Desafían de esta forma las definiciones estatales de la nacionalidad, dando cuenta del modo de pensar las identificaciones de las jóvenes generaciones con cierta autonomía de las pertenencias indicadas por el Estado7. Esta expectativa colectiva adulta hacia los jóvenes seguramente resulta en tensiones con visiones lineales de la integración y la inclusión y con las formas del nacionalismo que perduran en gran medida en las escuelas.

Ahora bien, si para muchos adultos migrantes, la misma participación en los eventos festivos, recreativos, laborales y organizativos de la Colectividad es leída como una señal de pertenencia al colectivo, no resulta claro que así sea interpretada esta presencia por los mismos jóvenes. Por el momento esto solo se nos plantea como una pregunta en torno a la cual seguimos indagando.

Para comprender la complejidad de las apuestas identitarias de la localidad es necesario advertir que la preocupación porque sus hijos y nietos sigan siendo bolivianos, coexiste con la apuesta familiar y colectiva porque se incluyan en la sociedad argentina. Se habilita así las dobles pertenencias, en proyectos que parecen resultar adecuados a la condición transnacional de vida del colectivo. Esta doble apuesta también resulta en tensiones con la forma estatal y en particular la escolar de pensar las identificaciones nacionales.
Los proyectos de inclusión se traducen entre otras cosas en la expectativa de una escolaridad más larga (finalización el ciclo secundario), posibilidad que se asocia para muchos padres a "ser alguien en la vida". La expectativa de la continuidad de la escolaridad fue un tema que apareció espontáneamente en las charlas con padres y referentes de las organizaciones. Se asoció frecuentemente a la posibilidad de cortar las historias familiares de pobreza: que no tengan que trabajar en la quinta, que no sean como yo que deje la escuela y acá estoy.

Registramos en el seguimiento de la situación educativa de los hijos de bolivianos reiterados y constantes esfuerzos de los padres porque vayan a la considerada mejor escuela del barrio (la escuela de la ruta): cambio formal del domicilio, trámites y gestiones en el distrito escolar, etc. Esta escuela es, significativamente la más desmarcada de "lo boliviano". La misma diferencia se traslada, con particularidades, a las escuelas secundarias que funcionan al lado de ambas escuelas primarias.

La continuidad de la escolarización se presenta así para los migrantes bolivianos en Buenos Aires como una condición de integración a la sociedad nacional y también de superación de la imagen de pobreza y sumisión. También parece funcionar como un mecanismo de diferenciación al interior del colectivo. La escolarización marca de esas formas múltiples distinciones hacia dentro y hacia fuera de la comunidad de migrantes. Para abordar los sentidos que los colec- 
tivos bolivianos dan a la escolaridad puede ser importante considerar el lugar de la escuela en la zona andina de Bolivia. Según distintas investigaciones en Bolivia la escolarización es concebida por amplios sectores como un espacio de separación progresiva del mundo agrario y “catapulta social..." (Salazar, 2007: 52).

Posiblemente esto último, la situación de subalternidad en el contexto migratorio, el lugar que se supone estratégico de la escolaridad para la integración al nuevo territorio, sean parte de las claves que explican que las demandas de las familias migrantes a la escuela argentina se expresen en términos por lo general bastante lejanos a la interculturalidad. La inclusión de prácticas asociadas a "lo boliviano" en la escuela suelen tener, de parte de las mismas familias, un formato folklorizador: llevamos nuestra cultura, mostramos nuestras danzas, regalamos nuestra bandera, donamos instrumentos andinos para los actos escolares etc. De la escuela argentina, además de que dé lugar a estas expresiones culturales puntuales, se espera fundamentalmente mayor organización y disciplina (la recurrencia en este punto fue sorprendente). Debemos ser cuidadosos en la forma en que interpretamos esta demanda. El pedido a la escuela argentina de mayor orden y disciplina, lejos de limitarse solo a un deseo de integración, se legitima en el recuerdo de la escuela boliviana como más ordenada y con mayor legitimidad de la autoridad y la jerarquía adulta. Aunque ciertamente estas demandas no puedan leerse en clave intercultural, siguen, de alguna forma, dando indicios de la apuesta porque las jóvenes generaciones se socialicen en pautas similares a las que vivieron sus antecesores. Plantean asimismo complejas interpelaciones a la escuela argentina en su discurso modernizador y de respeto de los derechos del niño.

\section{Mandatos y experiencias escolares: dos escuelas en la tensión distinción-igualación}

Como recién mencionamos, la escuela primaria más prestigiosa "la escuela de la ruta", es la más demandada en el barrio, con mayor estabilidad del equipo docente y directivo, es, también, la escuela mas desmarcada de lo boliviano (Novaro, 2015). La escuela primaria más cercana a los mercados y predios de la Colectividad, ubicada frente a la plaza del centro del barrio, (pero que algunos actores escolares asocian al "fondo") se caracteriza por cierta inestabilidad del equipo directivo, problemas de infraestructura; a ella concurre proporcionalmente mayor cantidad de niños bolivianos, hijos o nietos de bolivianos. En ella es llamativa la baja matrícula y el hecho de que muchas familias, como vimos, intentan evitarla. Advertimos en distintos actores una representación sobredimensionada sobre la cantidad de migrantes en esta escuela. En la Colectividad nos dijeron "En esa escuela el $70 \%$ son paisanos”. Los registros, al menos en primaria dan cuenta de una presencia menor.

La situación de las escuelas secundarias pegadas a ambas primarias parece reproducir, en cierta medida esta diferenciación. 
La escuela secundaria de la ruta aparece en la dinámica del barrio como un espacio de relativa distinción y jerarquía. El edificio tiene dos pisos, es muy luminoso, pintado con murales, siempre está muy limpio. Las aulas son espaciosas y ventiladas. En la escuela media suelen acabarse las vacantes. La directora nos expresó en más de una ocasión su interés porque los chicos tuvieran información de la universidad (incluso en el 2016 nos convoco a dar una charla para ello). Expreso además su preocupación por la pérdida de matrícula en los grados superiores y por la discontinuidad en los estudios universitarios. También los jóvenes de la escuela de la ruta valoran esta institución como la mejor escuela del barrio.

La escuela de la plaza es mucho más pequeña, los años deben turnarse (por la mañana de primero a tercer año, por la tarde cuarto, quinto y sexto) ya que las aulas no alcanzan para incorporar en el mismo horario a todos los jóvenes. A pesar de los problemas edilicios, la dirección y varios docentes de la secundaria trabajan con continuidad en la institución hace algunos años. En numerosos encuentros la directora nos expreso su intención de vincularse a las familias y también de proponer cierta flexibilización del régimen académico, considerando tanto la situación de estudiantes con sobreedad, como de aquellos que sostienen actividades domésticas y laborales.

Un interesante contrapunto entre una y otra escuela fue trazado por una profesora de plástica que trabaja en ambas instituciones al señalar el hecho de que en la escuela de la plaza los chicos bolivianos están más cómodos, hablan de sus experiencias por ejemplo en las ferias y mercados y los frecuentes viajes a Bolivia, mientras que los chicos bolivianos de la escuela de la ruta silencian estas situaciones. La presencia en actos escolares en esta última mostró en general la fuerza de un discurso uniformizador de lo nacional argentino como referencia de identificación y el lugar acotado para la expresión de otras estéticas.

Marcadas o no, registramos en ambas instituciones intentos pero también limitaciones para aproximarse a las experiencias formativas no escolares de los jóvenes, reconocer y valorar su conocimiento del barrio. Notamos asimismo que si bien hay matices entre ambas instituciones, frecuentemente lo nacional argentino sigue teniendo una gran centralidad en la enseñanza de las ciencias sociales y en los actos escolares. El lugar para otras expresiones e identidades tiene un lugar en ocasiones puntuales, pero por lo general es ciertamente limitado y frecuentemente folklorizado.

\section{7. ¿Experiencias escolares en clave intercultu- ral? Argentinos o bolivianos, o argentinos y bolivianos}

Numerosas situaciones de interacción con los jóvenes permiten pensar en un uso selectivo y contextual de sus identificaciones nacionales. 
Momentos para hablar y callarse de su pasado familiar. Situaciones donde el olvido o el intento de olvidar y desmarcarse de lo boliviano parecen marcar sus trayectorias; otras donde el recuerdo, la nostalgia y el deseo de seguir siendo se imponen.

El registro de situaciones escolares da cuenta de esta alternancia. En la escuela lo boliviano suele transformarse en una marca de estigmatización. Este aspecto ha sido registrado por numerosos investigadores y por nosotros mismos en textos previos (Neufeld, 1999; Domenech, 2007; Novaro et al., 2011). Seguramente por ello la escuela no parece un espacio demasiado amigable para hacer explícitas las pertenencias familiares particulares. Sin embargo, registramos también situaciones escolares donde estas referencias se muestran por iniciativa de los mismos jóvenes.

A continuación comentamos tres situaciones vividas en la escuela de la Plaza que ilustran este contraste: la participación de jóvenes de familias bolivianas en una fiesta nacional argentina, los silencios en una secuencia de clase sobre Conquista de América, los diálogos posteriores con jóvenes bolivianos en la escuela.

En 2018 acompañamos diversas situaciones escolares en esta escuela. Dos de ellas resultaron especialmente significativas con relación a las marcaciones y autoadscripciones de los jóvenes: el festejo del 9 de julio (día de la Independencia argentina) y la secuencia sobre la explotación minera en Potosí colonial con alumnos de histo- ria de segundo año. Al concluir el año charlamos con los jóvenes en grupos reducidos. A continuación, un relato sintético de estas situaciones procurando identificar los sentidos que se jugaron en las distintas escenas.

La fiesta del 9 de julio se celebró en la plaza que se ubica frente a la escuela. Esto en sí mismo rompió con cierto acartonamiento que caracteriza los actos escolares. Los alumnos del secundario encabezados por la directora salieron de la escuela y dieron vuelta a la plaza portando una enorme bandera argentina. La parte protocolar del acto alterno referencias típicas al heroísmo de "nuestros patriotas", con alusiones a la hermandad latinoamericana. Varios bailes de chicos de la primaria y la secundaria mostraron las típicas danzas tradicionales argentinas (zambas y chacareras de los varones con bombacha de gaucho y camisa blanca, las mujeres con polleras celestes y blancos, peinadas con trenza). Estos bailes fueron en general coordinados por una preceptora del colegio. Hasta ahí, más o menos lo esperable en una festividad patria.

Avanzado el festejo notamos que en el patio de la secundaria varios chicos con trajes de tinkus y caporales practicaban solos los pasos de estos bailes. Los encabezaba un joven que enseñaba a los demás. Ningún adulto los coordinaba. Estuvieron un largo rato allí mientras se desarrollaba el acto en la plaza, ensayando los pasos y la coreografía, corrigiéndose. Parecían divertidos y entusiasmados. Finalmente se ubicaron en la puerta de la escuela y se sacaron muchas fotos. 
A continuación, llamados por la directora, mostraron estos bailes en la plaza, nuevamente, sin ningún adulto coordinándolos. Uno de los jóvenes (el más entrenado en los bailes y que en el patio corregía los pasos a los demás) se enojó en algún momento porque bailaban muy descoordinados y dio por terminada la muestra. Siguieron sacándose fotos, riendo y abrazándose.

En el relato de la festividad se advierte el contrapunto entre la iniciativa de las autoridades escolares en el despliegue del folklore argentino y el protagonismo de los jóvenes en las danzas bolivianas. Charlas posteriores con la directora nos mostraron que esta iniciativa y apropiación del acto de parte de los jóvenes es parte de un dispositivo que la misma escuela propone y habilita. En estas charlas resultó significativo el relato de eventos donde las tensiones con los jóvenes se agudizan, por ejemplo cuando plantean invitar sin anticipación bailarines de la colectividad ajenos a la escuela.

El protagonismo de los chicos y su iniciativa de profundizar la apertura de la escuela hacia el afuera es revelador en sí mismo de su interés en dar lugar a personas eimágenes que irrumpen en lo que la escuela propone. Además lo es que la escuela habilite estos espacios y que la marcación de límites provoque tensiones que permanentemente deben ser negociadas. En definitiva, algo de otras voces e imágenes circula por iniciativa de los propios colectivos, la escuela abre y cierra estos espacios, la interculturalidad parece presente cuando las autoridades se arriesgan a per- der parte del control y confiar la visibilización de presencias diversas desde el punto de vista nacional, étnico, y también generacional.

Con posterioridad al festejo concurrimos semanalmente entre septiembre y noviembre para acompañar a una docente de historia en el desarrollo de la secuencia sobre la conquista de América. La docente expreso reiteradas veces su interés en aproximarse a los alumnos, valorar sus historias, dialogar y escucharlos. La secuencia incluía la alusión especifica a Potosí (de donde, repetimos, viene la mayoría de las familias migrantes del barrio). En este año los hijos de familias bolivianas constituía un $40 \%$ de la matricula, los chicos de nacionalidad boliviana cerca del 30\%. La docente, complementó las actividades del aula con la organización del festejo del 12 de octubre donde organizo un ritual a la Pachamama y, con nuestro apoyo, convoco a la presidenta de la CBE. Los chicos participaron activamente en este evento. Sin embargo, en la secuencia sobre Potosí no hubo, de parte de los chicos, ninguna mención a la significatividad del cerro, la mina y la explotación en sus propias vidas y trayectorias familiares.

Las alusiones si existieron en charlas más privadas que al finalizar las clases mantuvimos con ellos. En las charlas nos llamó la atención el contraste en la respuesta a la pregunta directa: que te acordás de Bolivia, contestada en varios casos con frases como "nada, me cuentan y me olvido de todo" y los relatos pormenorizados sobre parientes que trabajan actualmente en la mina, el 
detalle de herramientas para trabajar en la mina y en el campo, sobre creencias en el diablo, sobre prácticas como sacrificios de niños, etc.

La alternancia de mostrar y ocultar las referencias a Bolivia en las tres situaciones resulta muy clara. El silencio de las propias experiencias y las trayectorias familiares en las instancias más cercanamente vinculadas a la transmisión institucionalizada de conocimientos (o sea, la clase en el aula) también, sobre todo porque se trataba una temática "cercana" a los alumnos y a cargo de una docente que mostró reiteradas veces la intención de aproximarse, escuchar y valorar sus trayectorias.

\section{Conclusiones: desafíos a la interculturalidad educativa en contextos de migración}

Se advierte en Escobar que Bolivia está presente en los proyectos pasados y presentes de las familias y de los jóvenes bolivianos, en la forma en que generan estrategias de visibilización y ocultamiento; está presente en el modo en que los jóvenes se involucran en las redes y las formas organizativas generadas por sus padres y los referentes del barrio. Bolivia está presente en el modo en que, en contextos escolares, "recuerdan y olvidan" estratégicamente sus historias familiares y referencias colectivas. Se advierte la presencia de Bolivia y también de Argentina en el modo en que los jóvenes viven sus proyectos de inserción y permanencia en un territorio distinto al de origen de sus padres.
Las experiencias y voces de los jóvenes muestran la creatividad para seguir siendo o definiéndose como bolivianos y seguir estando en Argentina. Esto constituye un primer desafío intercultural al sistema educativo en tanto desborda proyecciones polares que suelen registrarse en la escuela que imaginan que los jóvenes o bien renunciaran a sus historias y referencias familiares, o bien quedaran sujetos pasivamente a las mismas.

Los sentidos que las familias ponen en la escolarización también desafían imágenes tradicionales del sistema educativo. La escuela se presenta para los migrantes bolivianos en Buenos Aires como una condición de integración a la sociedad nacional y también de superación de la imagen de pobreza y sumisión. La escolarización marca múltiples distinciones hacia dentro y hacia fuera de la comunidad de migrantes, diferenciando trayectorias al interior del colectivo. Tal como explicitamos, no resulta claro que el colectivo migrante proyecte en la escuela expectativas de inclusión de sus marcas culturales particulares (clave en el que suelen oficializarse los proyectos escolares denominados interculturales), sino mas bien demandas por la calidad y disciplinamiento. Estas últimas son legitimadas frecuentemente en el recuerdo de las escuelas bolivianas. La asociación de la escuela como un espacio de integración pero también la expectativa de que la escuela socialice en continuidad con pautas tradicionales de la escuela boliviana sin duda plantean desafíos a los enfoques interculturales, 
pero también a los discursos de derechos.

Las tres escenas relatadas en el último punto dan cuenta de significativos avances del sistema educativo, pero también de muchos aspectos pendientes.

En la escuela frecuentemente nos encontramos con que ciertas prácticas asociadas a Bolivia (los viajes, la inserción laboral) son vistas como situaciones que atentan contra la continuidad del ciclo escolar. Asimismo, se presupone que la participación en festividades cívicas bolivianas, aleja a los jóvenes del nacionalismo argentino con el que se espera se identifiquen. Por el contrario hemos visto que en las fiestas comunitarias atravesadas por la situación de transnacionalidad, los jóvenes son interpelados como bolivianos pero también como argentinos.

Así, se registran en las escuelas límites para trabajar con la coexistencia de los proyectos comunitarios por seguir siendo y por integrarse exitosamente a la Argentina, limites que dan cuenta de las dificultades para replantear ciertos presupuestos fundantes: la asociación del deseo de distinción con el encapsulamiento y de los proyectos de integración con la asimilación. Hacen evidente la necesidad de replantear visiones lineales de la inclusión, sostenidas sobre el supuesto de que formar parte de la nueva nación supone renunciar a la de origen.

Desde estos presupuestos parecieran no poder verse, ni habilitarse las dobles pertenencias que en los jóvenes del barrio son evidentes. Creemos que en la lógica local una propuesta escolar atenta a la interculturalidad debería considerar fundamentalmente este aspecto de las dobles identificaciones de las familias bolivianas y de las jóvenes generaciones.

La escena referida al silencio de los jóvenes en clase cuando se habla de Potosí colonial nos permite abrir en el cierre algunos interrogantes. Seguimos preguntándonos cuanto del formato escolar, de la forma de presentar el conocimiento desde una lógica exclusivamente disciplinar condiciona este silencio. Profundizar la indagación en este sentido es fundamental para que la interculturalidad este presente no solo en las imágenes festivas y las evocaciones puntuales, sino en las situaciones cotidianas de enseñanza y aprendizaje en el aula, enriqueciendo y desafiando los conocimientos que la escuela legitima para todos.

\section{Referencias citadas:}

Bartlett, L., Rodríguez, D., \& Oliveira, G. (2015): “Migração e educação: Perspectivas socioculturais”. Educação e Pesquisa, 41,1153-1171. Disponible en http:// dx.doi.org/10.1590/S1517-9702201508144891

Caggiano, S. (2014): "Riesgos del devenir indígena en la migración desde Bolivia a Buenos Aires". Identidad, etnicidad y desigualdad. Amérique Latine Histoire et Mémoire. Les Cahiers ALHIM [Online], 27/2014. Disponible en http://alhim.revues.org/4957 
Cerrutti, M., y Binstock, G. (2012): Los estudiantes inmigrantes en la escuela secundaria. Integración y desafios. Buenos Aires como Fondo de las Naciones Unidas para la Infancia (UNICEF).

De Oliveira Santos, M. (2014): “Migração e educação: analisando o cotidiano escolar na Região Metropolitana do Rio de Janeiro”. PerCursos, 15(28), 95-119.

Dietz, G. y Mateos, L. (2011): “Interculturalidad y educación intercultural: hacia un marco conceptual comparativo". En: Interculturalidad y Educación Intercultural en México. Un análisis de los discursos nacionales e internacionales en su impacto en los modelos educativos mexicanos. México, Secretaría de Educación Pública.

Diez, M.L. (2016): “Interculturalidad y Migración: reflexiones sobre política educativa e identificaciones étnicas y nacionales en Argentina”. Revista Caja Negra Num. 12, enero-junio 2016, pp. 133-145. Benemérita Universidad Autónoma de Puebla, México.

Domenech, E. (2007): “Migraciones contemporáneas y pluralismo cultural en la Argentina: el discurso oficial y las prácticas escolares". Cartografias da Imigração: Interculturalidade e Políticas Públicas, Lugar: Porto Alegre; p. 19-45.

García, I. (2003): "Los hijos de inmigrantes extranjeros como objeto de estudio de la sociología”. Anduli: Revista andaluza de ciencias sociales $\mathrm{n}^{\circ}$ 3, 27-46.

Gavazzo, N. (2011): "Acceso diferencial a la ciudad.
Identificaciones y estereotipos entre los hijos de inmigrantes bolivianos y paraguayos en Buenos Aires". Social and Spatial Inclusion of International Migrants. Paper Series, 8. Recuperado en: www.unescochair-iuav.it

Gibson, M. (1998): Promoting Academic Success among Immigrant Students: Is Acculturation the Issue? Educational Policy, 12(6), 615-633. Disponible en http://dx. doi.org/10.1177/0895904898012006002

Gil Araujo, S; Pedone, C. (2013): "Políticas públicas $\mathrm{y}$ discursos sobre familia, migración y género en contextos de inmigración/emigración”. En Karasik G (Coord) Migraciones Internacionales. Reflexiones y estudios sobre la movilidad territorial contemporánea. Ed. Ciccus, Buenos Aires.

Grimson, A. (1999): Relatos de la diferencia y la igualdad. Los bolivianos en Buenos Aires. Buenos Aires: Eudeba.

Gordillo, G. y S. Hirsch, (2010): “La presencia ausente: invisibilizaciones, políticas estatales y emergencias indígenas en la Argentina”, en: Gastón Gordillo y Silvia Hirsch (comps.), Movilizaciones indígenas e identidades en disputa en la Argentina, Buenos Aires, La crujía.

Grimson, A. (1999): Relatos de la diferencia y la igualdad: los bolivianos en Buenos Aires, Buenos Aires, Eudeba.

Hamann, E. y Zúñiga, V. (2011): “Schooling and the everyday ruptures transnational children encounter 
in the United States and Mexico". In C. Coe, R. Reynolds, D. Boehm, J. Hess, \& H. Rae-Espinosa (Eds.), Everyday ruptures: Children, youth, and migration in global perspective (pp. 141-160). Nashville, TN: Vanderbilt University Press.

Hecht, A.; García, M.; Enriz, N.; Diez; M.L. (2015) "Interculturalidad y educación en Argentina: reflexiones a propósito de un concepto polisémico". En: Compilador/es: G. Novaro, A. Padawer y A.C. Hecht (comp.) Educación, pueblos indígenas y migrantes. Reflexiones desde México, Brasil, Bolivia, Argentina y España. Buenos Aires: Biblos. Páginas 43-63.

Martinez, L. (2015): “Infancia, Diferencia y Desigualdad aportes en la clave de los feminismos poscoloniales", Clivajes. Revista de Ciencias Sociales-Año II, Núm. 4, julio-diciembre 2015.

Neufeld, M. R., y Thisted, A. (Eds.) (1999): De eso no se habla: Los usos de la diversidad sociocultural en la escuela. Buenos Aires: Eudeba

Novaro, G. et al. (2011): "Interculturalidad y educación. Cruces entre la investigación y la gestión". NOVARO, Gabriela (comp.). La interculturalidad en debate. Experiencias formativas y procesos de identificación en niños indígenas y migrantes. Buenos Aires: Editorial Biblos, 265-281.

Novaro, G. (2015). “Familias, asociaciones y escuelas: tensiones en las identificaciones nacionales de niños migrantes".

Novaro, G. (2016): “Migración boliviana, discursos civilizatorios y experiencias educativas en Argentina".
Linhas Críticas: 77-93.

Novaro, G. (2018): "Dances in migratory, community and school contexts: identity marks and folklorised presences". Ethnography and Education, 13(3), 340-358.

Orellana, M. F. (2009): Translating childhoods: Immigrant youth, language and culture. New Brunswick, NJ: Rutgers University Press.

Pacecca, M. I. (2010): “Migrantes de ultramar, migrantes limítrofes. Políticas migratorias y procesos clasificatorios. Argentina, 1945-1970". Revista Temas de Antropología y Migración, $\mathrm{N}^{\circ}$ 0, 8 -34.

Padawer, A., Palacios, M. G., Enriz, N., Borton, A., \& Hecht, A. C. (2015): “Conocimientos en intersección: regulaciones estatales y experiencias formativas cotidianas en dos grupos indígenas de Argentina”. G. Novaro, L. Santillán, A. Padawer y L. Cerletti, Niñez, regulaciones estatales y procesos de identificación. Experiencias formativas en contextos de diversidad y desigualdad. Argentina: Editorial Biblos.

Portes A; Rumbaut, R. G. (2010): “Legados. La historia de la segunda generación inmigrante”. Barcelona: Hipatia Editorial.

Salazar, C. (2007): “Ser alguien, ser boliviano. Niños, adolescentes y jóvenes en el umbral de la ciudadanía”. Cuaderno de Futuro $\mathrm{N}^{\circ} 24$, Bolivia, PNUD.

Sayad, A. (2010): "La doble ausencia. De las ilusiones del emigrado a los padecimientos del inmigrado". Es- 
paña, Anthropos.

Terigi, F. (2007): “Los desafíos que plantean las trayectorias escolares" FUND. SANTILLANA. III Foro Latinoamericano de Educación Jóvenes y docentes. La escuela secundaria en el mundo de hoy.

Toscano, A. y M. Diez (coord.) (2012): Adolescentes y Secundaria Obligatoria. Centros de Escolarización Secundaria para Adolescentes y Jóvenes. Ed. UNGS-Unicef, Buenos Aires.

UNLA/ UNICEF (2015): Niñez, migraciones y derechos humanos. Hacia una democratización de las políticas migratorias en Argentina. Universidad Nacional de Lanús, Fondo de Naciones Unidas para la Infancia, Buenos Aires

UNIPE (2019): “Estudiantes indígenas en escuelas argentinas, una población invisible”. Observatorio Educativo. Universidad Pedagógica Nacional. Año $2 \mathrm{~N}^{\circ} 4$, Buenos Aires.

\section{Notas:}

${ }^{1}$ Me refiero a los proyectos colectivos desarrollados en la Facultad de Filosofía y Letras de la Universidad de Buenos Aires que posteriormente recibieron tambien el apoyo financiero del Conicet y de la Agencia Nacional de Promoción Científica y Tecnológica.

2De acuerdo al último censo del año 2010 la población de origen paraguaya supera el 30\% de los extranjeros (550.713 personas), en tanto la de origen boliviana es del 19\% (345.272 personas).
${ }^{3}$ La Ley de Educación Nacional No 26.206 (2006) establece a la EIB como una de las ocho modalidades educativas, la define como un derecho de los pueblos indígenas. Vale destacar que salvo el capítulo especifico dedicado a esta modalidad intercultural (cap XI) no hay menciones a la misma en el resto del texto de la ley.

${ }^{4}$ La ley migratoria establece el derecho a la educación para la población inmigrante cualquiera sea su condición de regularidad. En consonancia, la Ley de Educación Nacional ( $\left.\mathrm{N}^{\circ} 26.206 / 2006\right)$ establece que deben disponerse las medidas necesarias para garantizar a las personas migrantes el acceso a los distintos niveles educativos y las condiciones para la permanencia y el egreso.

5Entre los jóvenes de 14 a 19 años, es decir en las edades esperadas de asistencia al nivel medio, solo el $56.5 \%$ de los adolescentes de origen boliviano (...) se encontraban asistiendo a un establecimiento educativo. En cambio, en la población total de la Argentina la proporción era del 72,6\%. (Cerruti y Binstock, 2012: 13).

${ }^{6}$ Este trabajo centró su atención en las valoraciones sobre el trabajo en contextos comunitarios y escolares, en las identificaciones nacionales y las festividades en ambos espacios.

7Tanto la normativa argentina como la boliviana aplican el ius soli: Son argentinos nativos los nacidos en el territorio de la República Argentina (Ley de nacionalidad y ciudadanía 21795). Son bolivianos 
Migración boliviana y escuela secundaria en Argentina: reflexiones en clave intercultural.

Autoctonía. Revista de Ciencias Sociales e Historia, Vol. III, $\mathrm{N}^{\circ} 2$

de origen Los nacidos en el territorio de la República

(Nueva Constitución Política del Estado). 